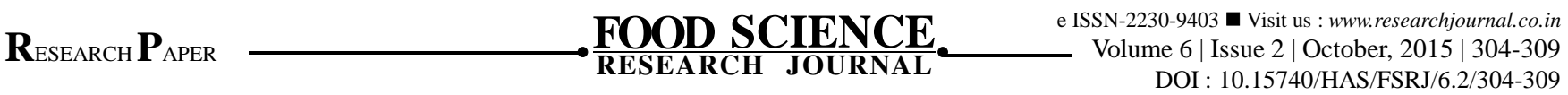

\title{
Assessment of dietary intake by food frequency questionnaire among pregnant women
}

\author{
Navjot Kaur and Priya Singla
}

\begin{abstract}
Pregnancy is marked by high accumulation of nutrients in the form of maternal and foetal tissue growth. Nutrition during pregnancy is of great importance because foetus draws its nourishment from mother. Child bearing imposes great strain, even it is normal physiological process it increases considerably the nutritional requirements of mother. The present study was also conducted to assess the dietary intake of pregnant women. About 60 subjects were selected randomly from Ludhiana city. Information regarding socio-economic status, medical history, food frequency consumption pattern, anthropometric measurements was recorded by filling up questionnaire. Daily nutrient intake was calculated by using 'dietcal software'. Complications were present in majority of subjects. Majority of subjects consumed wheat, milk, fats and oils, sugar and jaggery on the daily basis from all the food groups. Intake of macronutrients i.e. energy, protein as well as micronutrients such as folic acid, vitamin B12, iron and calcium intake was found to be inadequate as compared to RDA.
\end{abstract}

Key Words : Dietary intake, Food Frequency questionnaire, Medical history and pregnant women

How to cite this article : Kaur, Navjot and Singla, Priya (2015). Assessment of dietary intake by food frequency questionnaire among pregnant women. Food Sci. Res. J., 6(2): 304-309.

\footnotetext{
Author for correspondence :

NAVJOT KAUR, Department of Food and Nutrition, Punjab Agricultural

University, LUDHIANA (PUNJAB) INDIA

Email : drnavjotgill@pau.edu

Associate Authors' :

PRIYA SINGLA, Department of Food and Nutrition, Punjab Agricultural

University, LUDHIANA (PUNJAB) INDIA
} 